patients with Hodgkin's disease. ${ }^{4}$ Kupffer's cells may be one source of endogenous pyrogen in man and it is interesting that sustained fever is more common in patients with hepatic Hodgkin's disease. All our patients had hepatic Hodgkin's disease and fever of several days' duration. Human leucocytes produce endogenous pyrogen in vitro when exposed to endotoxin: this response is blocked by the cytotoxic agent actinomycin C. ${ }^{5}$ Production of endogenous pyrogen in our patients may have been inhibited by the cytotoxics, the homoeostatic mechanisms controlling temperature causing prolonged rebound hypothermia.

Though we have no certain explanation for the abrupt onset of hypothermia, these observations raise several points. How often does hypothermia complicate cytotoxic treatment? Hypothermia often escapes diagnosis because low reading thermometers are not used. As it may be a serious complication in the old and weak, patients with sustained fever during cytotoxic treatment should be carefully observed.

${ }^{1}$ Koriech OM. Hypothermia and hypotension in Hodgkin's disease. Br Med f $1981 ; 282: 1583$

2 MacKenzie J. Hypothermia and hypotension in Hodgkin's disease. $\mathrm{Br}$ Med f $1981 ; 283: 139$.

${ }^{3}$ Pattison CW. Hypothermia and hypotension in Hodgkin's disease. $\mathrm{Br} \mathrm{Med}$ 7 $1981 ; 283: 438$.

4 Bodel P. Pyrogen release 'in vitro' by lymphoid tissue from patients with Hodgkin's disease. Yale F Biol Med 1974;47:101-12.

${ }^{5}$ Nordlund JJ, Root RK, Wolf SM. Studies on the origin of human leucocyte pyrogen. $\mathcal{F}$ Exp Med 1970;131:727-43.

(Accepted 25 fanuary 1983)

Royal Victoria Infirmary, Newcastle upon Tyne NE1 4LP

M J JACKSON, BMEDSCI, MRCP, medical registrar

S J PROCTOR, MRCP, MRCPATH, senior lecturer in medicine and haematology

Department of Radiotherapy, Newcastle General Hospital, Newcastle upon Tyne NE4 6BE

R C F LEONARD, MD, MRCP, lecturer in oncology

Correspondence to: Dr M J Jackson.

\section{Cycling in patients with chronic airflow limitation}

Patients with chronic airflow limitation have reduced exercise tolerance when walking due to breathlessness.' Conventional treatment-for example, with $\beta_{2}$ agonists or portable oxygen -leads to only modest improvement in exercise tolerance (roughly $10 \%$ )..$^{23}$ While walking is a relatively efficient means of propulsion, cycling is considerably better. ${ }^{4}$ We have investigated cycling in patients with severe chronic airflow limitation.

\section{Present study}

We studied seven patients (five men; mean age $61.6 \pm$ SD 11.0 years) with severe chronic airflow limitation (forced expiratory volume in one second $0.80+0.241$; forced vital capacity $2 \cdot 21+0.821$ ). All were non-smokers and were being maintained with inhaled bronchodilators, which were withdrawn on study days. Variables studied were breathlessness and exercise tolerance, and ventilation and oxygen consumption.

Patients cycled around a rectangular tarmac track $(100 \times 80 \mathrm{~m}$; Wapping Sports Centre) using three cycles-a bicycle (Dawes Ladybird: five gears, $15 \mathrm{~kg}$ ), an NHS tricycle (Pashley Ltd: three gears, $25 \mathrm{~kg}$ ), and a lightweight tricycle (K Rogers Ltd: 10 gears, $15 \mathrm{~kg}$ ). Walking tests were performed across the width of the track. Patients were instructed to go as far as they could in six minutes on each of the three cycles and during a six minute walk. The distance travelled and breathlessness induced $(10 \mathrm{~cm}$ visual analogue scale; range not breathless to extremely breathless) were noted. Tests were performed in random order, with an hour's rest between tests.

In a separate study we compared ventilation, oxygen consumption, and distance travelled in the seven patients when $(a)$ walking for six minutes at their own reduced pace and $(b)$ tricycling for six minutes at the normal walking pace of AAW. Patients wore a close fitting facemask, and total ventilation and oxygen consumption were measured for each six minute period (Oxylog; P K Morgan Ltd).
RESULTS

Patients adapted quickly to the cycles, though several (especially those with bicycle experience) had initial difficulty cornering on the tricycle.

Exercise tolerance and breathlessness-Patients cycled between three and four times further than they walked in six minutes $(289+75 \mathrm{~m})$. Of the three cycles, the greatest distances were achieved with the lightweight tricycle $(1147+197 \mathrm{~m})$ and the bicycle $(1055+278 \mathrm{~m})$ : distances covered with these machines were significantly greater than with the NHS tricycle $(833+192 \mathrm{~m})$ $(p<0.05)$. Patients were significantly less breathless after the lightweight tricycle (visual analogue scale $6 \cdot 8 ! 2 \cdot 2)$ than after the NHS tricycle $(8 \cdot 1+0 \cdot 8)$, the bicycle $(7 \cdot 6+2 \cdot 8)$, and walking $(7 \cdot 9: 2 \cdot 7)$, despite having travelled the greatest distance $(\mathrm{p}<0 \cdot 05)$.

Ventilation and oxygen consumption-When patients tricycled at the walking pace of AAW they travelled at twice their own walking speed $(4.47 \div 0.79 \mathrm{~km} / \mathrm{h} v 2.26 \div 0.73 \mathrm{~km} / \mathrm{h} ; \mathrm{p}<0.001)$. This was achieved at lower ventilation $(20.5+5.21 / \mathrm{min} v 22.3: 6.51 / \mathrm{min})$ and with a lower oxygen consumption $(577: 183 \mathrm{ml} / \mathrm{min} v 662: 182 \mathrm{ml} / \mathrm{min}$ ); hence the efficiency of tricycling was more than twice that of walking.

\section{Comment}

We tested three readily available cycles. The bicycle was chosen for lightness and ease of mounting. The NHS tricycle is designed for use by mentally and physically disabled adults. It is heavy and not ideal for use with breathless patients but was tested because it is prescribable. The lightweight tricycle was modified from a tricycle designed for racing by fitting standard handlebars. It is light, stable, and has a low rolling resistance.

Patients with severe airflow limitation increased the distance travelled in six minutes up to fourfold by cycling. Patients travelled furthest and were least breathless on the lightweight tricycle. Tricycling was more than twice as efficient as walking in terms of oxygen consumption, and also patients could adopt a good breathing posture on the tricycle by fixing the upper thorax and may be able to sustain a greater ventilation with less discomfort. The tricycle is stable at slow speeds and if a patient became breathless he can stop without dismounting, being in an ideal posture to recover. Shopping and supplemental oxygen can be carried with minimal disadvantage.

We believe that lightweight tricycles might be useful in rehabilitating patients with chronic airflow limitation. They are relatively cheap to buy $(£ 250)$ and maintain and are a good form of exercise. All of the patients were severely disabled by breathlessness when walking and were amazed to have covered between half a mile and one mile $(0.8$ and $1.6 \mathrm{~km})$ in six minutes when cycling. The improvement in distance travelled on the tricycle compared with walking $\left(297^{\prime \prime}\right)$ was almost 30 times greater than achieved with conventional medical treatment ${ }^{2}$ (table).

Mean percentage improvements in distances travelled in six minutes' walking and using the three cycles. (Seven patients with severe chronic airflow limitation)

\begin{tabular}{lccc}
\hline & Salbutamol & $\begin{array}{c}\text { Portable } \\
\text { oxygen }\end{array}$ & Tricycle \\
\hline Improvement in 6 minute distance $\left({ }^{\prime \prime}\right)$ & 10 & 12 & 297
\end{tabular}

We thank Renza Cradduck, Jane Jones, and Meg Lunt for technical help, P K Morgan Ltd for the loan of the Oxylog, and K Rogers Ltd for the loan of the lightweight tricycle. This work was supported by grants from the clinical research committee of the Brompton Hospital and the Tobacco Advisory Council.

1 McGavin CR, Gupta SP, McHardy GJR. Twelve minute walking test for assessing disability in chronic bronchitis. Br Med f 1976;i:822-3.

2 Leitch AG, Hopkin JM, Ellis DA, Marchant S, McHardy GJR. The effect of aerosol ipratropium bromide and salbutamol on exercise tolerance in chronic bronchitis. Thorax 1978;33:711-3.

Woodcock AA, Gross ER, Geddes DM. Oxygen relieves breathlessness in pink puffers. Lancet $1981 ;$ i:907.

1 Whitt FR, Wilson DG. In: Bicycling science: ergonomics and mechanics. Cambridge, Massachusetts: MIT Press, 1974:5.

(Accepted 4 fanuary 1983)

Brompton and London Chest Hospitals, London

ASHLEY A WOODCOCK, MD, MRCP, registrar

MARGARET JOHNSON, MB, MRCP, registrar

DUNCAN GEDDES, MD, FRCP, consultant physician

Correspondence to: Dr A A Woodcock, St James's Hospital, Balham, London SW12 $8 \mathrm{HW}$

.

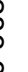

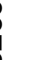

